\title{
Social inhibition of barpressing in undeprived rats
}

\author{
RICHARD DENI \\ George Peabody College, IMRID Box 154, Nashville, Tennessee 37203
}

and

\author{
BRUCE W. JORGENSEN \\ University of Hartford, West Hartford, Connecticut 06117
}

\begin{abstract}
Barpress behavior was assessed in experimentally naive undeprived rats during exposure to three companion conditions: trained companion, untrained companion, and no companion. Non-nutritive sucaryl solution was presented as barpress-contingent reinforcement. Though overall levels of barpressing were low, the responding during exposure to either trained or untrained companions was significantly lower compared to the no-companion condition. This observation of companion-induced inhibition with undeprived rats compliments previous work testing social facilitation at high and low levels of thirst drive (Levine \& Zentall, 1974). The findings also support the theoretical predictions of Zajonc (1965) regarding companion effects.
\end{abstract}

According to the theory of social facilitation offered by Zajonc (1965), a companion can affect a subject in two basic ways, depending upon the subject's level of training on a particular task. The companion's presence was said to enhance performance of well-learned behavior and inhibit the performance of new responses (p. 270).

In their study of companion effects with previously trained rats, Levine and Zentall (1974) raised an important argument with respect to Zajonc's theory of social facilitation $(1965 ; 1968)$. Zajonc has assumed that the presence of a companion is a source of generalized drive. This generalized drive was offered as the causal factor in behavior changes as a function of exposure to a companion. Levine and Zentall have reported the effects of different levels of "basic" drive (thirst) on social facilitation. They found that the effects of thirst drive and the companion-induced drive summated.

They tested four groups of rats: (1) high thirst drive with companion present, (2) low thirst drive with companion present, (3) high thirst drive with companion absent, and (4) low thirst drive with companion absent. Their results support Zajonc's theory. Groups where the companion was present performed significantly more barpressing compared to groups where the companion was absent. In addition, as would be expected, groups under the influence of high deprivation barpressed significantly more than groups under low deprivation. These two effects were obtained without a significant interaction of the two variables of drive and companion.

The Levine and Zentall study showed that

This paper is sponsored by Hardy C. Wilcoxon, who takes full editorial responsibility for its content. Preparation of this manuscript was partially supported by NICHHD Grant No. 00973. deprivation level can summate with companioninduced drive. Thus, it follows that a better assessment of the effect of companion-induced drive will be obtained when subjects are not deprived at all.

The present study measured barpressing in previously untrained rats during exposure to either trained, untrained, or no companion. Non-nutritive reinforcer was presented contingent upon barpressing. Where Levine and Zentall's work has shown the effects of high and low "basic" thirst drive on social facilitation, the present study sought to establish social facilitation effects for subjects not influenced by "basic" thirst drive.

\section{METHOD}

\section{Subjects}

The subjects were 22 untrained adult male hooded rats (Long-Evans strain) aged $180-200$ days at the start of the experiment. They were housed individually in steel cages from the time of weaning, and they were fed water and Lab Chow ad lib.

\section{Companions}

Four adult hooded rats similar in age to the subjects were used as companions. Two of these were designated trained companions and maintained on a 23 -h water deprivation schedule. The remaining two rats were designated untrained companions and were fed Lab Chow and water ad lib.

\section{Apparatus}

A modified Scientific Prototype \#A100 operant chamber was used. The chamber was divided into two equal-sized compartments by a clear Plexiglas partition: one a companion compartment, the other a subject compartment. A rat lever and Lehigh Valley \#1527 liquid dispensing unit were located in each compartment. The companion compartment fluid dispenser was filled with tap water and released $.05 \mathrm{~g}$ of solution at each operation. The subject compartment dispenser was filled with a $10 \%(\mathrm{v} / \mathrm{v})$ sucaryl (Abbott Labs) and tap water solution, also releasing $.05 \mathrm{~g}$ at operation. The reinforcement schedules for both companions and subjects were CRF, controlled by electromechanical devices located in an 
Table 1

Mean Number of Barpresses for Six Daily 30-Min Sessions

\begin{tabular}{llr}
\hline Group & n & Mean \\
\hline Trained Companion Present & 7 & 6.44 \\
Untrained Companion Present & 7 & 7.61 \\
No Companion Present & 8 & 12.79 \\
\hline
\end{tabular}

Note $-F(2,19)=3.98, p<.05$. Trained vs. no companion and untrained vs. no companion, $p<.05$, Duncan's multiple range test.

adjacent room. White noise was provided through a speaker mounted $1 \mathrm{~m}$ above the chamber. Noise level was $80 \mathrm{~dB}$, measured at the roof of the chamber.

\section{Procedure}

Trained companions were trained to barpress for water reinforcement. Training continued until they reached stable rates of 150-200 responses per 30 -min daily session. Untrained companions were not trained; their rat levers were locked during all sessions. Individual trained and untrained companions were alternated during the course of the procedure.

Subjects were randomly assigned to three groups: (1) trained companion group, (2) untrained companion group, and (3) no companion group. All subjects remained undeprived throughout the course of testing. Subjects were placed in the operant chamber along with the assigned companion for 6 daily 30 -min sessions, and their barpressing was recorded. Subjects were reinforced with $10 \%$ sucaryl solution.

\section{RESULTS}

Barpress performance for the three treatment groups is given in Table 1 . Barpressing by previously untrained subjects exposed to either a trained or untrained companion was significantly lower compared to the no-companion condition.

\section{DISCUSSION}

Zajonc has predicted that the presence of a companion will inhibit the performance of new responses (Zajonc, 1965, p. 270). The experimental findings reported here support this prediction. Barpressing was significantly inhibited during exposure to either trained or untrained companions compared to the no-companion condition. Since appetitive thirst drive in these subjects was not altered, and was indeed near a zero level, the assumption made by Zajonc that companion-induced drive causes social facilitation was strengthened. However, one must first agree with Zajonc's original interpretation of the evidence associating increased generalized drive with companion exposure (Zajonc, 1965, 1968). Perhaps the source of evidence needed now, in studies of animal companion effects, is assessment of drive-related changes in subjects at the time of companion exposure and behavioral testing. Oniy then can the question of drive as a causal or mediating factor be answered adequately. The Levine and Zentall work and the present study provide evidence that the companion effect, whether enhancing well-learned behavior, or inhibiting new responses, can be obtained under a broad range of "basic" drive levels.

\section{REFERENCES}

Levine, J. M., \& Zentall, T. R. Effect of a conspecific's presence on deprived rats' performance: Social facilitation vs. distraction/imitation. Animal Learning \& Behavior, 1974, 2. 119-122.

ZAJONC, R. B. Social facilitation. Science, 1965, 149, 269-274.

ZAJonc, R. B. Social facilitation in cockroaches. In E. C. Simmel, R. A. Hoppe, \& G. A. Milton (Eds.), Social facilitation and imitative behavior. Boston: Allyn \& Bacon, 1968.

(Received for publication February 19, 1976.) 